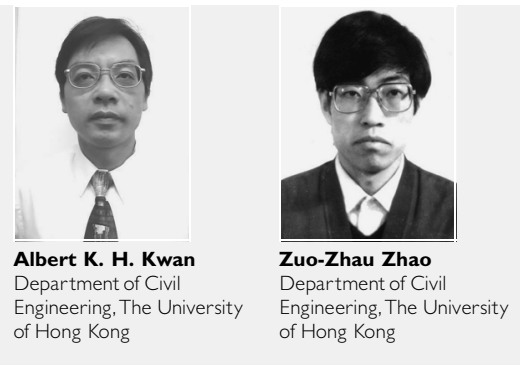

\title{
Cyclic behaviour of deep reinforced concrete coupling beams
}

\author{
A. K. H. Kwan and Z.-Z. Zhao
}

Six half-scale models of reinforced concrete coupling beams with span/depth ratios $\leqslant 2.0$ were tested under reversed cyclic load by a newly developed test method that can accurately simulate the boundary conditions of coupling beams in coupled shear wall structures. Five of them were conventionally reinforced and one was diagonally reinforced. Span/depth ratio and reinforcement layout were the main structural variables studied. Test results revealed that the deep conventionally reinforced coupling beams behaved quite differently from the ordinary beams in frame structures. Generally, shear failure was more likely to occur. Moreover, the additional longitudinal reinforcement bars (those placed near the centroidal axis) could contribute significantly to bending strength and therefore lead to an increase in shear demand. Nevertheless, the measured drift ratios of the conventionally reinforced coupling beams still reached $3 \cdot 6-5 \cdot 7 \%$, which are not small for deep coupling beams. On the other hand, it was found that the provision of diagonal reinforcement radically changed the load resisting mechanism and significantly improved the energy dissipation capacity of the coupling beam. However, it had not improved the deformability of the coupling beam.

\section{INTRODUCTION}

Extensive studies have been carried out in the past decades to investigate the structural behaviour of reinforced concrete coupling beams. ${ }^{1-7}$ A detailed review of these studies has been given by the authors elsewhere. ${ }^{7}$ It was generally observed that deep conventionally reinforced concrete coupling beams (those with span/depth ratios $\leqslant 2 \cdot 0$ ) tend to fail in a non-ductile manner, with shear-tension failure occurring when the stirrups provided are not sufficient to resist the whole shear force and shear-compression or shear-sliding failure occurring when the stirrups are designed to take the whole shear force. As a result, they often do not possess the demanded ductility for the coupled shear wall structure to resist earthquake loads. In order to improve their ductility, several alternative reinforcement detailing methods have been proposed and investigated. ${ }^{5,6}$ Particularly, the diagonal reinforcement and the rhombic reinforcement layouts have been found to yield better ductility.

However, it has been found that the boundary conditions of the coupling beams had not been properly simulated during the model tests. ${ }^{7}$ In most previous test methods, ${ }^{3,5,6}$ the rotations of the two ends of the coupling beam model were not controlled to be equal. Although at the elastic stage this would not cause any problem, after the appearance of cracks, which would render the coupling beam unsymmetrical, the rotations at the two ends of the model could become very different. ${ }^{3}$ In a real coupled shear wall structure, the rotations of the two walls at the ends of a coupling beam are always equal and thus a coupling beam model under test should satisfy the displacement boundary condition that the rotations at the two ends are equal at all times. Without satisfying this boundary condition, the measured behaviour after the appearance of cracks and the ductility factor determined might not be realistic. To study the post-peak behaviour and evaluate the ductility of coupling beams, a test method that can accurately simulate the displacement boundary condition of a real coupling beam is required.

The local deformation at the beam-wall joints is another problem needing consideration. Due to stress concentration, local deformation occurs at the beam-wall joints at both the elastic and inelastic stages. The local deformation at the elastic stage is due entirely to the elastic deformation of the wall panels near the joints and has been quite well researched. ${ }^{8}$ After the appearance of cracks near the beam-wall joints and at higher applied load, further local deformation occurs due to bond-slip of the longitudinal reinforcement bars and inelastic deformation of the wall panels near the joints. Such local deformation could cause a substantial increase in lateral deflection and rotation of the coupling beams, as had been observed by Paulay ${ }^{2}$ and Barney et al. ${ }^{4}$ At the post-peak stage, localised yielding of the longitudinal reinforcement bars at the beam-wall joints dramatically increases the joint rotations leading to further increase in lateral deflection/rotation of the coupling beams. Aktan and Bertero ${ }^{9}$ have found that the local joint rotations could amount to $80 \%$ of the total measured rotation of the coupling beam. Therefore, in the model tests of coupling beams, the local deformation at the beam-wall joints should be allowed for.

Traditionally, the ductility of a structure or a structural component is assessed in terms of a ductility factor defined as the ratio of the deflection/rotation at ultimate state to the corresponding deflection/rotation at yield. Such a ductility factor is quite sensitive to the deflection/rotation at yield and a small change in the deflection/rotation at yield could cause a relatively large difference in the ductility factor. Consequently, 
a structure may have a relatively small ductility factor just because it has a relatively large deflection/rotation at yield. For example, comparing the two coupled shear wall models tested by Paulay and Santhakumar, ${ }^{10}$ the model with conventionally reinforced coupling beams actually had a larger deflection at failure, although relatively the conventionally reinforced coupling beams had a smaller ductility factor. In view of such a pitfall, Sözen ${ }^{11}$ had suggested a design criterion based on storey drift (relative lateral displacement divided by storey height) rather than on ductility factor. He claimed that there is no reason to reject a framing system just because it is not capable of developing a displacement ductility factor of six to eight if yield corresponds to a storey drift of almost 1\% (a fairly large storey drift from a damage control point of view).

After many years of development, the displacement-based design for earthquake resistant structures is gaining general acceptance. ${ }^{12}$ In this design method, a building is designed to have the desired level of seismic performance by imposing a certain displacement (or more precisely, drift) demand onto the building structure. Booth et al. ${ }^{13}$ have compared the provisions for seismic design of reinforced concrete buildings in different countries and found that the maximum allowable storey drift at the ultimate limit state ranges from $1 \cdot 0$ to $2 \cdot 5 \%$. While ensuring that the maximum allowable storey drift is not exceeded, the building structure must also be designed to have sufficient deformability to withstand the maximum allowable storey drift. Hence, the maximum allowable storey drift is also a displacement or drift demand. In line with increasing emphasis on drift demand, deformability is becoming more important than ductility as a measure of seismic performance.
Although alternative reinforcement layouts have been proposed, conventionally reinforced concrete coupling beams are still widely used for coupled shear wall structures in many seismic regions, especially those in Asia. It is, therefore, of practical importance to investigate how the conventionally reinforced concrete coupling beams perform during earthquakes. This paper reports an experimental study on the cyclic behaviour of deep conventionally reinforced concrete coupling beams using a newly developed test method that maintains equal rotations at the two ends of the coupling beam model and allows for local deformation at the beam-wall joints. For comparison, a diagonally reinforced concrete coupling beam was also tested. Based on the test results, the general behaviour, failure mode, ductility, deformability and energy dissipation capacity of the coupling beams were studied.

\section{EXPERIMENTAL PROGRAMME}

\section{I Specimens and variables}

A total of six coupling beam specimens with dimensions and details as shown in Fig. 1 were fabricated and tested. They were basically half-scaled and could be divided into two series. The first series comprised of specimens CCB1, CCB2, CCB3 and CCB4, which have similar longitudinal reinforcement ratios and similar transverse reinforcement ratios but different span/depth ratios of $1 \cdot 17,1 \cdot 40,1.75$ and $2 \cdot 00$, respectively. The second series comprised of specimens CCB1, CCB11 and CCB12, which have the same span/depth ratio of 1.17 but different layouts of reinforcement. Table 1 lists the structural parameters of the six specimens.
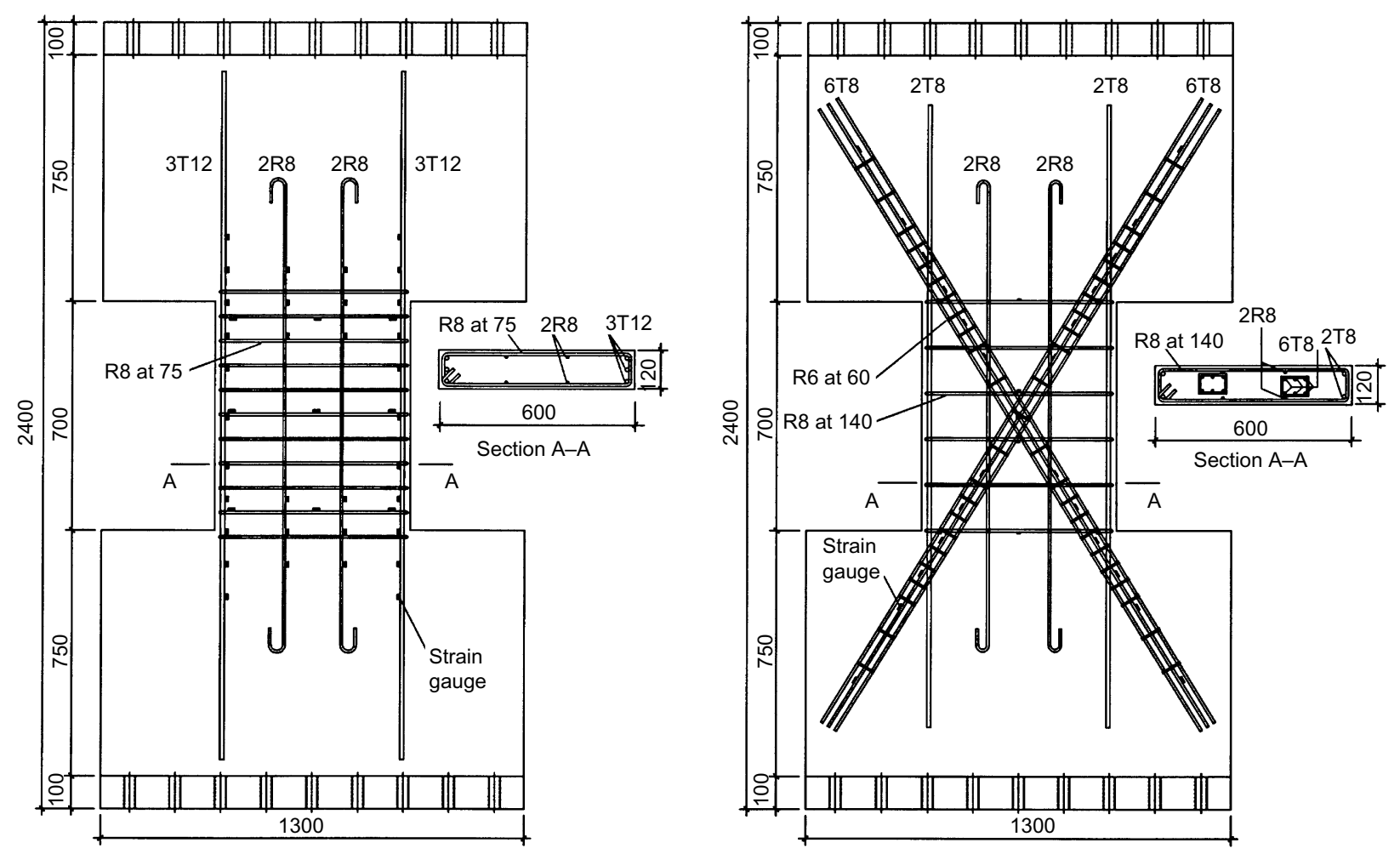

Fig. I. Dimensions and details of the beam specimens tested: (a) specimen CCB I; (b) specimen CCB I I 


\begin{tabular}{|c|c|c|c|c|c|c|}
\hline Specimen & Depth: mm & $\begin{array}{l}\text { Span/depth } \\
\text { ratio }\end{array}$ & $\begin{array}{c}\text { Main } \\
\text { longitudinal } \\
\text { reinforcement } \\
\text { reinforcement }\end{array}$ & $\begin{array}{c}\text { Additional } \\
\text { longitudinal } \\
\text { reinforcement }\end{array}$ & Stirrups & Diagonal \\
\hline $\begin{array}{l}\text { CCBI } \\
\text { CCB2 } \\
\text { CCB3 } \\
\text { CCB4 } \\
\text { CCBII } \\
\text { CCBI2 }\end{array}$ & $\begin{array}{l}600 \\
500 \\
400 \\
350 \\
600 \\
600\end{array}$ & $\begin{array}{l}1 \cdot 17 \\
1 \cdot 40 \\
1 \cdot 75 \\
2 \cdot 00 \\
1 \cdot 17 \\
1 \cdot 17\end{array}$ & $\begin{array}{c}3 \text { TI2 } \\
2 \text { TI2 + T8 } \\
2 \text { TI } 2+\text { T8 } \\
\text { ITI } 2+2 \text { T8 } \\
2 \text { T } 8 \\
3 T I 2\end{array}$ & $\begin{array}{l}4 R 8 \\
4 R 8 \\
2 R 8 \\
2 R 8 \\
4 R 8 \\
4 R 8\end{array}$ & $\begin{array}{l}R 8-75 \mathrm{c} / \mathrm{c} \\
\mathrm{R} 8-75 \mathrm{c} / \mathrm{c} \\
\mathrm{R} 8-75 \mathrm{c} / \mathrm{c} \\
\mathrm{R} 8-75 \mathrm{c} / \mathrm{c} \\
\mathrm{R} 8-140 \mathrm{c} / \mathrm{c} \\
\mathrm{R} 8-50 \mathrm{c} / \mathrm{c}\end{array}$ & $\begin{array}{l}- \\
- \\
- \\
- \\
6 \mathrm{~T} 8 \\
-\end{array}$ \\
\hline
\end{tabular}

strain gauges were used to measure the load, displacements and strains, respectively. The locations of the strain gauges are marked on the specimens shown in Fig. 1.

The specimens were tested under load control during the first two load cycles, with the maximum load set equal to $50 \%$ of the predicted yield load and the actual yield load (the load when the main or

At each end of a beam specimen, a rectangular end block $(1300 \times 750 \mathrm{~mm})$ having the same thickness as the beam and representing part of the wall connected to the beam was cast integrally with the beam as part of the specimen. These end blocks were to allow for local deformation at the beam-wall joints.

In each of the conventionally reinforced beam specimens, equal amounts of top and bottom longitudinal reinforcement were provided throughout the length of the beam. Additional longitudinal reinforcement was placed near mid-depth of the beam section. All longitudinal reinforcement bars in the beam were provided with generous anchorage into the end blocks. Stirrups were supplied in each specimen as shear reinforcement. On the other hand, the diagonally reinforced beam specimen CCB11 was designed according to the method proposed by Paulay and Binney. ${ }^{3}$

All beam specimens were cast of normal strength concrete with their planes lying horizontally. The average cube and cylinder strengths of the concrete at the time of the model tests were $52 \cdot 0$ and $37 \cdot 8 \mathrm{MPa}$, respectively. Two types of high-yield deformed bars (T12 and T8) were used as main longitudinal reinforcement, whereas mild steel plain round bars (R8) were used for the additional longitudinal reinforcement and the stirrups. The mean yield strengths of the T12, T8 and R8 bars were 525, 517 and $346 \mathrm{MPa}$, respectively.

\subsection{Test set-up and loading programme}

The test method used has been reported in an earlier paper ${ }^{14}$ and thus only an outline is presented here. As shown in Figure 3 of Reference 14 the beam specimen was erected with the longitudinal axis of the beam in the vertical direction, fixed at one end to a rigid ground beam and connected at the other end to a T-shaped steel loading frame. Shear load was applied to the specimen through the loading frame by an actuator, whose loading and support ends were pin-connected to the loading frame and a horizontal reaction frame, respectively. The line of action of the applied load was aligned to pass through the centre of the beam specimen. A rotation restraining mechanism consisting of two parallelogram-shaped pin-jointed trusses was installed to ensure that the rotations of the two ends of the specimen were equal.

The beam specimens were extensively instrumented to measure the applied load, displacements and strain distributions in the reinforcement bars. Load cell, displacement transducers and diagonal bars yielded) in the first and second cycles, respectively. After then, the average displacement in the two loading directions in the second cycle was taken as the yield displacement, $D_{y}$. Subsequent testing was conducted under displacement control at increasing displacement amplitude. Three load cycles were applied at each displacement amplitude, which was set equal to $2,3,4$, and so on, times the value of $D_{y}$ until the specimen failed. The ratio of the displacement amplitude to the yield displacement is denoted by $\mu$ in this paper.

\section{EXPERIMENTAL RESULTS}

\section{I General observations}

Before the main reinforcement bars started to yield, the beam specimens had similar crack patterns. In each beam specimen, two sets of cracks corresponding to the two opposite loading directions were formed. At the beginning, flexural cracks and combined flexural-shear cracks were found near the two ends of the beam specimen. Later on, some of the flexural cracks near the beam-wall joints formed by loads acting in opposite directions merged and developed into through cracks crossing the whole depth of the beam. Some fine cracks also appeared in the end blocks near the beam-wall joints. However, after the main reinforcement bars had yielded, the crack patterns of the six beam specimens became different, as shown in Fig. 2 .

In beam CCB1, inclined shear cracks appeared along one diagonal soon after the main bars yielded. These diagonal cracks passed through almost the entire span and divided the beam into two triangular halves interconnected by the stirrups. Measured strains in the stirrups showed that some of the stirrups yielded immediately after the formation of the diagonal cracks. When peak load was reached, nearly all the stirrups yielded. Yielding of the stirrups and the main bars led to wide opening of the shear and flexural cracks. Minor crushing failure of the concrete at the compression corners also occurred. When the inclined shear cracks opened to $10 \mathrm{~mm}$ width, the test was stopped and the beam specimen was regarded to have failed in shear-tension mode.

The cracks in beam CCB2 were similar to those in beam CCB1 except that CCB2 had more inclined shear cracks formed. Intersection of the inclined shear cracks caused by the applied loads in the two opposite directions divided the concrete of the beam into many small zones tied together by the reinforcement bars. Repeated opening and closing of these cracks due to load 


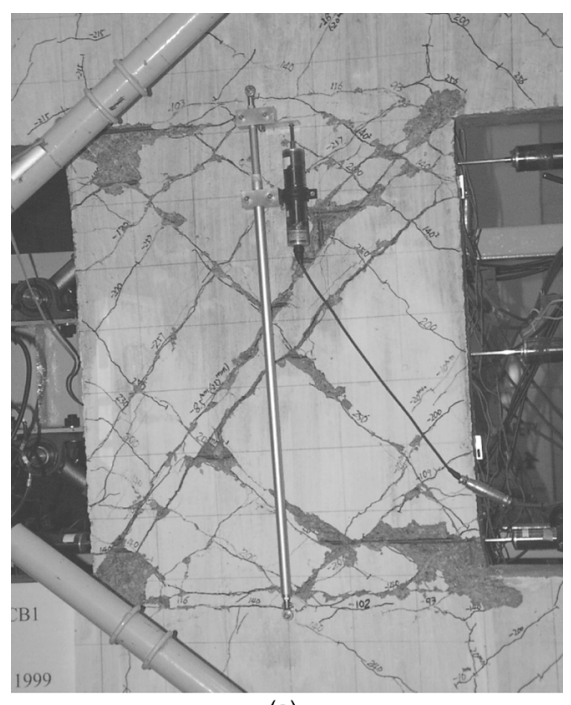

(a)

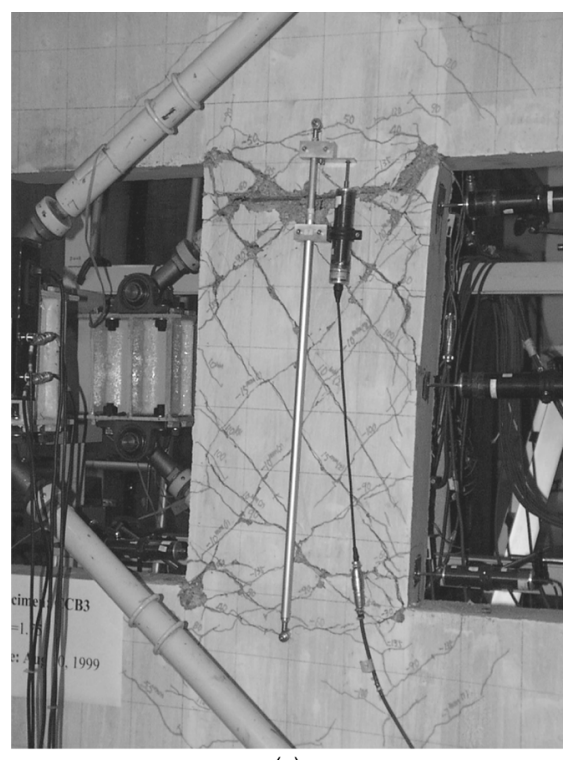

(c)

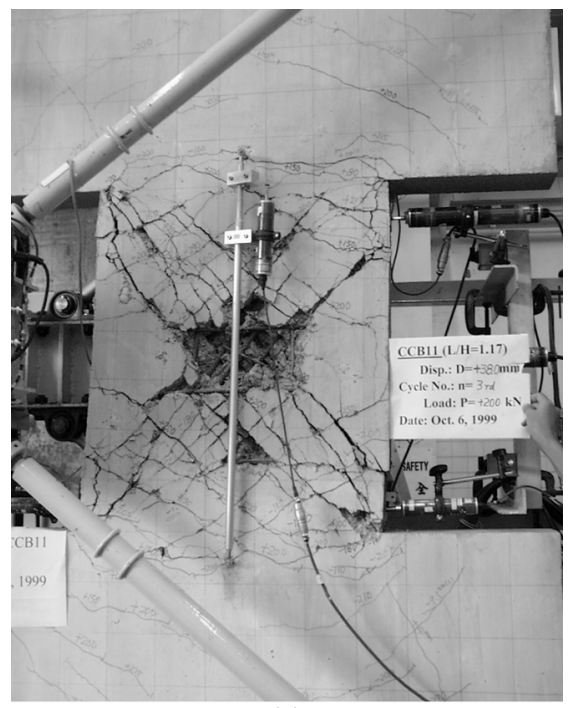

(e)

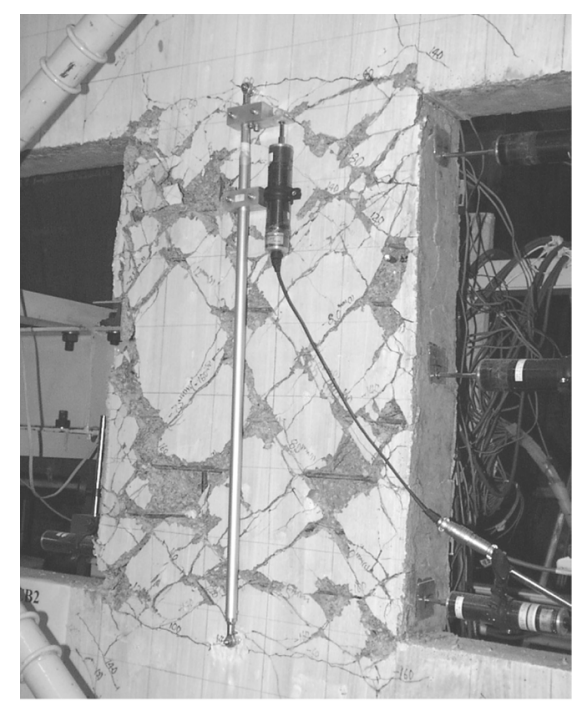

(b)

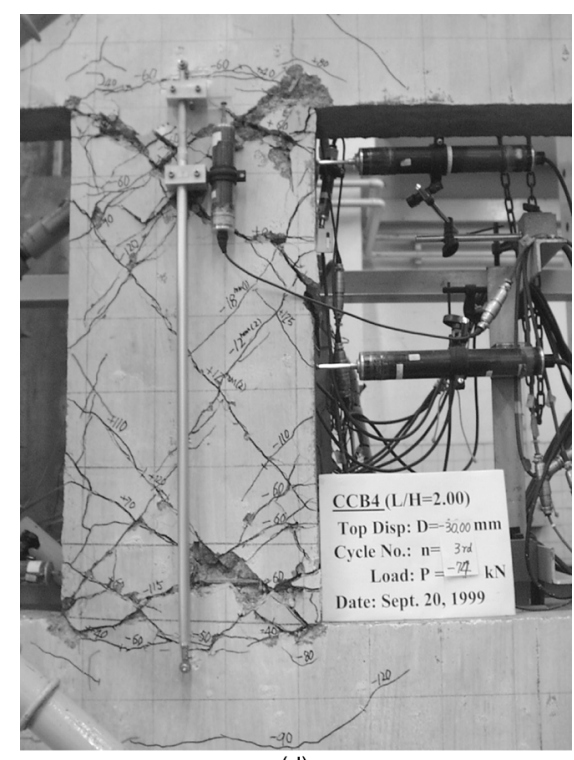

(d)

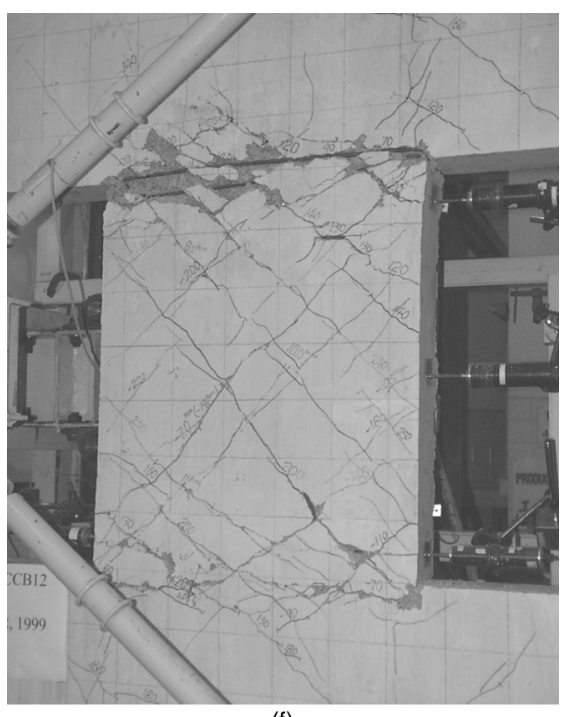

(f)

Fig. 2. Crack patterns and failure modes: (a) CCB I (shear-tension failure); (b) CCB2 (shear-compression failure); (c) CCB3 (shear-sliding failure); (d) CCB4 (filexural failure); (e) CCB II (diagonal bar buckling failure); (f) CCB I2 (shear-sliding failure) 
reversal led to serious spalling of the concrete. Although most stirrups had yielded at peak load, none of the inclined shear cracks had opened up. Eventually, the beam specimen failed in shear-compression mode.

In beams CCB3 and CCB4, all cracks were located near the beam-wall joints until the peak load was reached when inclined shear cracks started to appear near the centre of each beam. Although the appearance of the inclined shear cracks led to an immediate increase in tensile strain of the stirrups there, the stirrups near the centre remained unyielded. Even at the post-peak stage, only the stirrups near the beam-wall joints had yielded. Finally, beam CCB3 failed by shear-sliding due to sliding movement of a through crack near one beam-wall joint, while beam CCB4 failed by beam bending due to large local rotations of the two beam-wall joints.

In beam CCB11, which was provided with diagonal reinforcement, numerous inclined shear cracks were formed. These cracks remained very fine and stable until the peak load was reached. After reaching peak load, the diagonal reinforcement bars yielded in tension leading to a significant increase in crack width of the inclined shear cracks and large residual deflection when the applied load was removed. Moreover, the concrete near the centre of the beam was seriously damaged due to repeated opening and closing of the cracks there. Eventually, in one load cycle, the set of diagonal reinforcement bars under compression buckled near the centre of the beam and the load resisting capacity of the beam quickly dropped to less than $50 \%$ of the peak load.

In beam CCB12, which was similar to beam CCB1 except more stirrups were provided before the peak load was reached, the crack pattern was similar to that of beam CCB1. However, after the peak load was reached, beam CCB12 behaved quite differently; in beam CCB12, the inclined shear cracks did not open up even when virtually all the stirrups had yielded at the post-peak stage. In contrast, repeated opening and closing of the flexural cracks near the beam-wall joints led to gradual increase in crack width. Eventually, beam CCB12 failed by shear-sliding due to sliding movement of a through crack near one beam-wall joint, just like beam CCB3.

\subsection{Load-displacement curves}

Figure 3 depicts the loaddisplacement curves of CCB1, CCB4, CCB11 and CCB12. (The load-displacement curves of CCB2 and CCB3 are similar to that of CCB4.) It is seen that all the loaddisplacement curves obtained are highly hysteretic.

Generally, the loaddisplacement curves of the conventionally reinforced coupling beams exhibit substantial pinching, especially at large deflection amplitude. Such pinching would lead to rapid stiffness degradation and relatively small energy dissipation.

One possible reason for the pinching phenomenon was that the inelastic deflections of the conventionally reinforced coupling beams were due mostly to widening of the shear and flexural cracks, which remained open even when the applied load dropped to zero. When the applied load was reversed, the cracks had to be closed before the lateral resistance could recover, leading to small lateral resistance while the cracks were being closed and eventually pinching of the loaddisplacement curves.

In contrast, the load-displacement curve of the diagonally reinforced coupling beam exhibits no pinching and appears to be more stable. The reason behind this was that the applied load was resisted mainly by the tension in one set of diagonal reinforcement and by the compression in the other set of diagonal reinforcement. The compression developed in the concrete was not relied on and thus the opening/closing of the cracks in the concrete had relatively little effect on the lateral resistance of the coupling beam. However, buckling of the diagonal reinforcement bars could lead to sudden failure of the coupling beam. Therefore, sufficient lateral hoops should be provided along the diagonal reinforcement bars to keep the surrounding concrete in place and prevent, or at least delay, buckling failure.

\subsection{Strain distribution and axial elongation}

The strain distributions along the main longitudinal reinforcement bars in CCB1, CCB4 and CCB12, and that along the diagonal reinforcement bar in CCB11, are shown in Fig. 4. (The other two specimens had similar strain distributions to that of CCB4.) The variations of the axial strain at the midpoints of the main or diagonal bars in the beam specimens are presented in Fig. 5.

The strain distributions along the main longitudinal reinforcement bars in the conventionally reinforced coupling

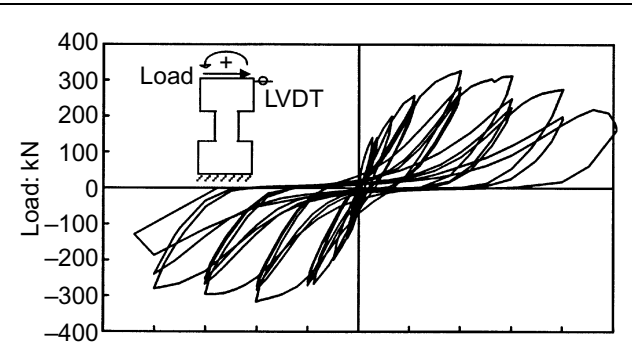

(a)

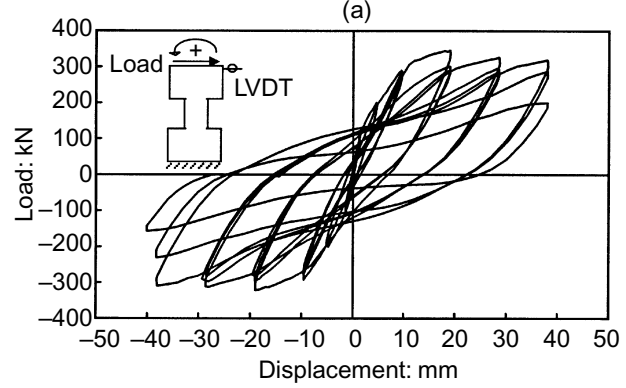

(c)

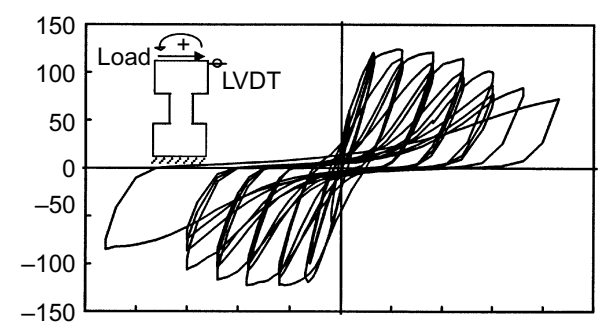

(b)

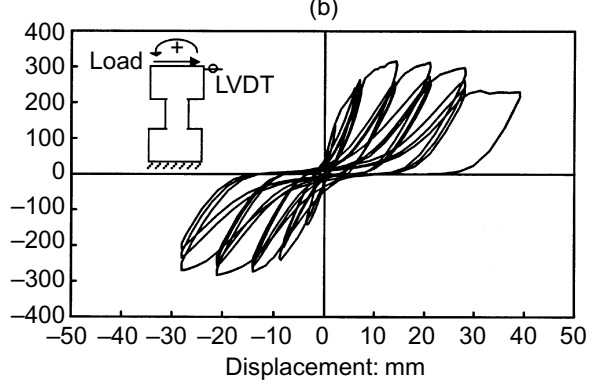

(d)

Fig. 3. Load-displacement curves: (a) CCBI; (b) CCB4; (c) CCBII; (d) CCBI2 


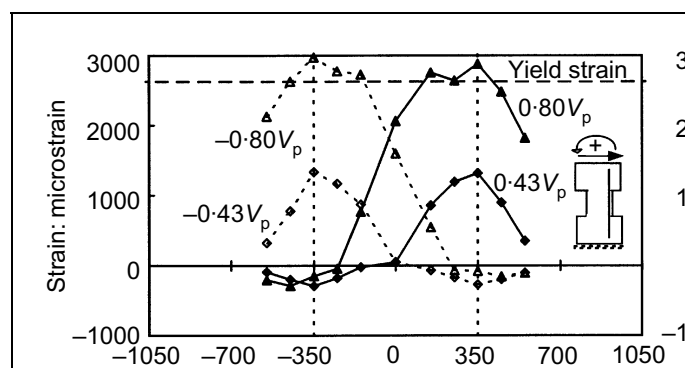

(a)

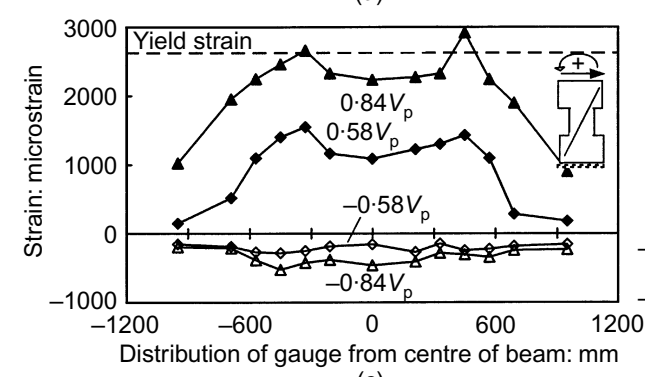

(c) (b)

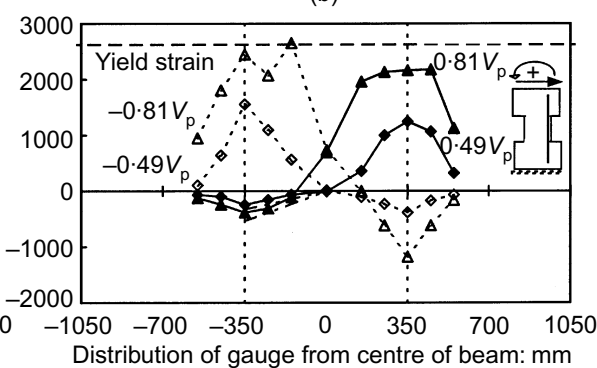

(d)

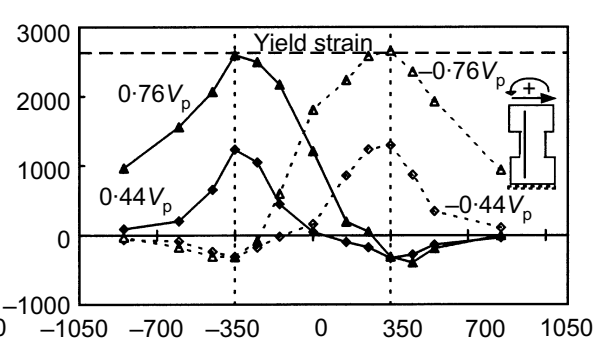

Fig. 4. Strain distributions along main or diagonal reinforcement bars $\left(V_{p}=\right.$ peak load): (a) CCBI; (b) CCB4; (c) CCBI I; (d) CCBI2

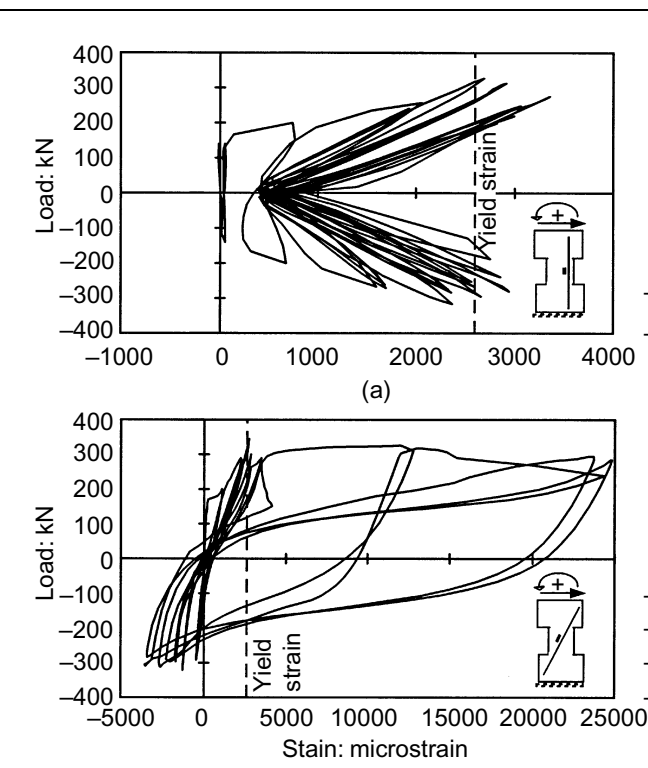

(c)

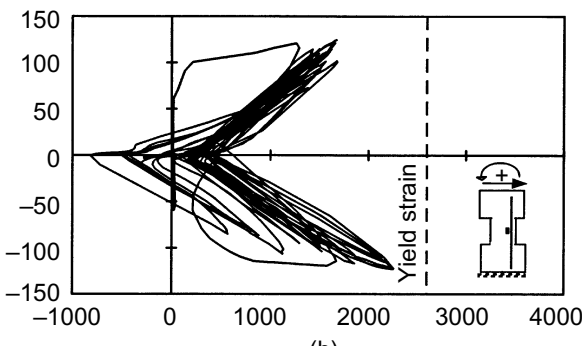

(b)

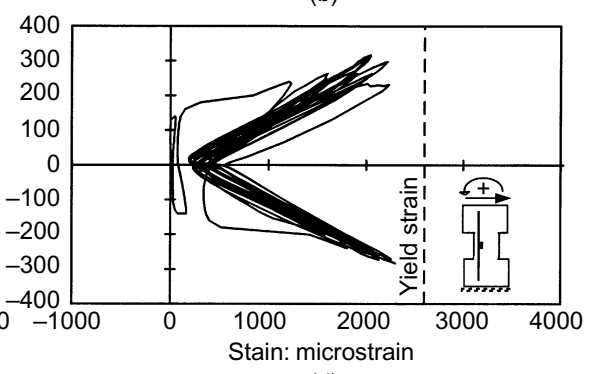

(d)
Fig. 5. Variations of strains at midpoints of the main or diagonal reinforcement bars: (a) $\mathrm{CCBI}$; (b) $\mathrm{CCB} 4$; (c) $\mathrm{CCB}$ I ; (d) $\mathrm{CCB} I 2$

load, it can be seen that after several load cycles, the main bars became always in tension regardless of the loading direction.

In the diagonally reinforced coupling beam, the strains were nearly constant along the diagonal reinforcement bars between two diagonal corners. At the same load level, the compressive strains in the diagonal bars were smaller than the corresponding tensile strains developed at the same location when the applied load acted in the opposite direction. This was probably because when the diagonal bars were in tension, the surrounding concrete did not help much in resisting the diagonal tension, but when the diagonal bars were in compression, the surrounding concrete shared part of the diagonal compression and hence reduced the axial shortening of the diagonal bars.

The measured strains in the additional longitudinal reinforcement bars (not shown in the figures) revealed that after the first two load cycles, all the additional bars developed substantial tensile stresses regardless of the loading direction. Except for some minor differences during the first few cycles, the variation of the tensile strains in the additional bars with the applied load was similar to that of the main bars. The additional bars eventually all yielded indicating that they

beams, when the applied loads were small, were very close to the contraflexural bending pattern predicted by normal beam bending theory. However, as the applied loads increased and the flexural-shear cracks in the beams developed, the strain distributions in the main reinforcement bars started to change. The zero strain points on the main bars gradually moved towards the concrete compression zones and eventually the whole lengths of the main bars were in tension. Although there was no bending moment at the centre of each beam, the steel strains there were not equal to zero. From the variation of the steel strains at midpoints of the main bars with the applied should have contributed significantly to the load resisting capacities of the coupling beams.

As the longitudinal or diagonal reinforcement bars yielded, the coupling beams elongated. Fig. 6 shows the average elongation strain (axial elongation divided by clear span length) of each of the specimens CCB1, CCB4, CCB11 and CCB12.

In each beam, before the yield load was reached, the axial elongation of the beam was very small and there was almost no residual elongation when the beam was unloaded. However, 


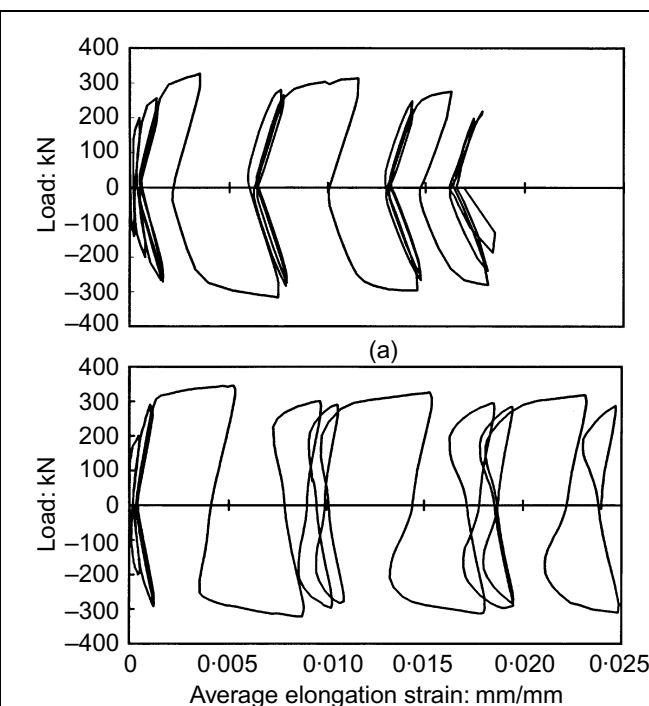

(c)

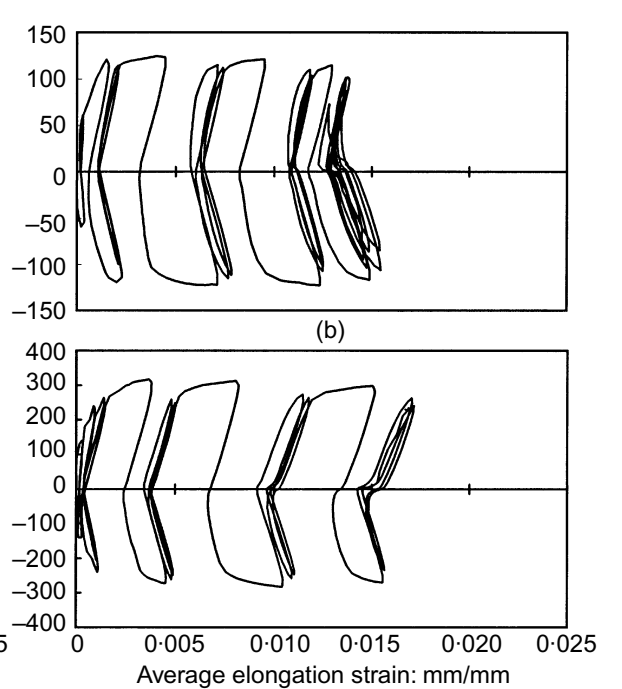

(d) after reaching the yield load, the axial elongation increased quickly. Every time, when the lateral displacement amplitude was increased, there was significant increase in axial elongation. Moreover, a substantial portion of the axial elongation remained as residual elongation when the applied load was removed. Consequently, all the coupling beams became longer after the tests. The maximum average elongation strains recorded for the conventionally reinforced beams were around $1 \cdot 2-2 \cdot 0 \%$ and that for the diagonally reinforced beam was about $2 \cdot 5 \%$.

\subsection{Local deformation at beam-wall joints}

Figure 7 shows the measured rotations along the beam axis of CCB1, CCB4, CCB11 and CCB12, at three displacement amplitudes of 1, 2 and 3 times the yield displacement, $D_{y}$ (i.e., at $\mu=1,2$ and 3). From these and other results, the following phenomena were observed.

(a) The rotation angles at the beam-wall joints remained relatively small and were approximately proportional to the applied loads before reaching the yield displacements, that is, before the main or diagonal reinforcement started to yield.

(b) Fairly large local rotations took place at the beam-wall joints when the main or diagonal reinforcement yielded.

(c) As the displacement increased, the local rotations at the beam-wall joints increased substantially due mainly to the gradual opening up of the flexural cracks near the beamwall joints to many times the corresponding values at first yield of the main or diagonal reinforcement.

(d) When the lateral displacements increased to three times the corresponding yield displacements, the additional displacements arising from the local rotations of the beamwall joints contributed about 35-70\% to the total lateral displacements of the coupling beams.

\section{PERFORMANCE EVALUATION}

\section{I Strength}

Table 2 shows the applied loads at first appearance of the inclined shear cracks, $V_{c}$, at first yield of the main or diagonal reinforcement bars, $V_{y}$, and at peak load, $V_{p}$, of each of the beam specimens tested. For comparison, the predicted strengths of the beam specimens evaluated in accordance with ACI $318-95^{15}$ are also listed in the table. For each coupling beam, two flexural strength values, $V_{y 1}$ and $V_{y 2}$, were obtained. $V_{y 1}$ was evaluated with the contribution of the additional longitudinal bars ignored, while $V_{y 2}$ was evaluated with the contribution of the additional longitudinal bars considered. The shear strength, $V_{\text {shear }}$, was evaluated as the sum of the shear capacity of the concrete, the shear capacity of the stirrups and the contribution to shear resistance of the diagonal reinforcement bars if present.

From the comparison, it can be seen that the experimental values of $V_{y}$ agree closely with the theoretical values of $V_{y 1}$, and the experimental values of $V_{p}$ agree closely with the theoretical values of $V_{y 2}$. The good agreement between $V_{y}$ and $V_{y 1}$ is because when the main or diagonal reinforcement bars first yielded, the tensile stresses developed in the additional longitudinal bars were still relatively small. The reason for the good agreement between $V_{p}$ and $V_{y 2}$ is that at peak load, the additional longitudinal bars had already yielded. Since $V_{y 2}$ is greater than $V_{y 1}$ by $12-23 \%$, the contribution of the additional longitudinal bars should be taken into account, as this would significantly increase the shear demand of the coupling beams.

For ease of interpretation, the applied loads are normalised in terms of nominal shear stresses as listed in Table 3. The nominal shear stresses are calculated as the corresponding applied loads divided by the effective area of the beam section. It is seen that the smaller the span/depth ratio of the coupling beam, the larger the nominal shear stress at peak load. The maximum nominal shear stresses of the conventionally reinforced coupling beams ranged from $3 \cdot 15$ to $4 \cdot 74 \mathrm{MPa}$, while that of the diagonally reinforced coupling beam was equal to 5.01 MPa. Hence, there appeared to be an upper limit of around $5 \mathrm{MPa}$ for the shear strength of a coupling beam made of normal concrete regardless of the reinforcement layout adopted.

\subsection{Ductility and deformability}

Figure 8(a) shows the envelopes of the cyclic loaddisplacement curves for the beam specimens CCB1, CCB2, CCB3 and CCB4. Although the four conventionally reinforced coupling beams had similar flexural reinforcement ratios and 


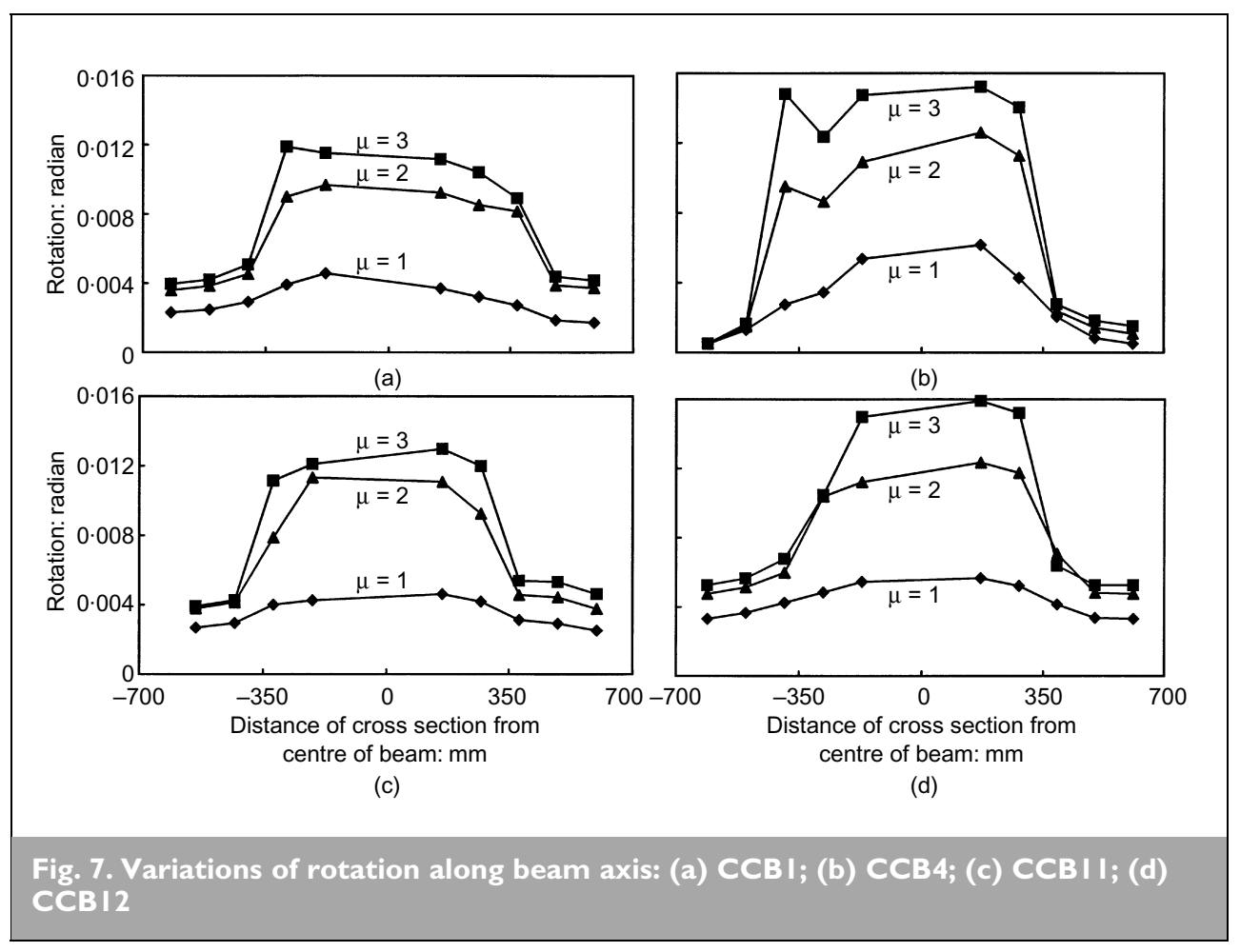

main or diagonal reinforcement bars, $D_{y}$, at peak load, $D_{p}$, and at the ultimate state, $D_{u}$. The ultimate displacement, $D_{u}$, is defined as the displacement when the load resistance of the beam had, after reaching the peak, dropped to $85 \%$ of the peak load. From these results, the ductility may be evaluated in terms of the displacement ductility factor, $\mu_{D}$, defined as $D_{u} / D_{y}$. Moreover, for deformability evaluation, the displacement at peak load, $D_{p}$, and the ultimate displacement, $D_{u}$, may be expressed in dimensionless forms as the drift ratio at peak load, $D_{p} / L$, and the ultimate drift ratio, $D_{u} / L$, in which $L$ is the clear span of the beam (equal to

similar shear reinforcement ratios, because of their different span/depth ratios, their load resisting capacities were different and they failed in different failure modes. Basically, as the span/depth ratio of such a

conventionally reinforced coupling beam decreased, the load resisting capacity increased but the ductility decreased. Figure 8(b) shows

\begin{tabular}{|c|c|c|c|c|c|c|}
\hline \multirow[t]{2}{*}{ Specimen } & \multicolumn{3}{|c|}{ Applied loads: kN } & \multicolumn{3}{|c|}{ Nominal shear stresses: $\mathrm{MPa}$} \\
\hline & at crack $V_{c}$ & at yield $V_{y}$ & at peak $V_{p}$ & at crack $\tau_{c}$ & at yield $\tau_{y}$ & at peak $\tau_{p}$ \\
\hline CCBI & 257 & 260 & 327 & $3 \cdot 72$ & $3 \cdot 77$ & $4 \cdot 74$ \\
\hline CCB2 & 184 & 190 & 227 & $3 \cdot 23$ & $3 \cdot 33$ & $3 \cdot 98$ \\
\hline CCB3 & 154 & 135 & 165 & $3 \cdot 42$ & $3 \cdot 00$ & $3 \cdot 67$ \\
\hline CCB4 & 114 & 110 & 123 & $2 \cdot 92$ & $2 \cdot 08$ & $3 \cdot 15$ \\
\hline CCBII & 180 & 290 & 346 & $2 \cdot 61$ & $4 \cdot 20$ & 5.01 \\
\hline $\mathrm{CCB} / 2$ & 200 & 240 & 317 & $2 \cdot 90$ & $3 \cdot 48$ & $4 \cdot 59$ \\
\hline
\end{tabular}
the envelopes of the cyclic load-displacement curves for the beam specimens CCB1, CCB11 and CCB12. Although these three beams have different reinforcement layouts, the envelopes of their load-displacement curves are very close to each other. This indicates that they had similar load resisting capacities and similar ductility.

Table 4 summarises the displacements of the specimens at first appearance of the inclined shear cracks, $D_{c}$, at first yield of the

$700 \mathrm{~mm}$ in the present study). The values of $\mu_{D}, D_{p} / L$ and $D_{u} / L$ are also shown in Table 4.

From Table 4, it can be seen that the displacement ductility factors of the six specimens tested varied from $4 \cdot 0$ to $6 \cdot 0$, being generally higher at a larger span/depth ratio. On the other hand, the drift ratios at peak load ranged from $1 \cdot 4$ to $2 \cdot 9 \%$, and the ultimate drift ratios ranged from $3 \cdot 6$ to $5 \cdot 7 \%$. However, the

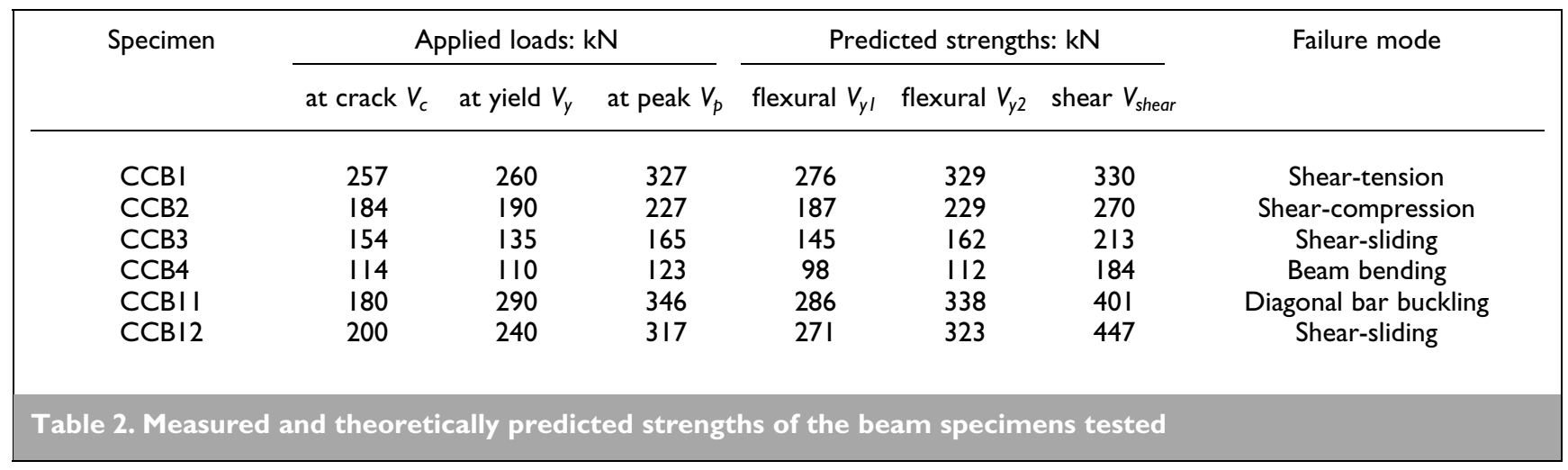




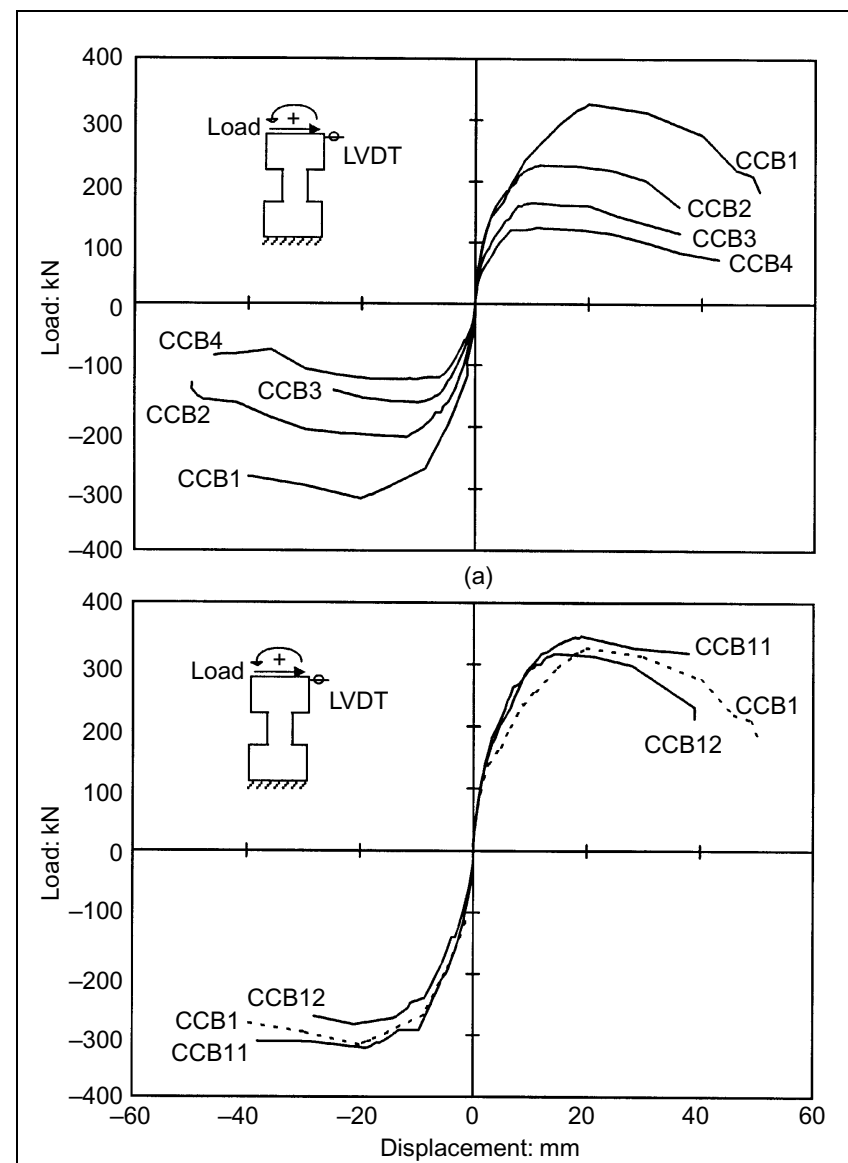

(b)

Fig. 8. Envelopes of the cyclic load-displacement curves: (a) specimens CCBI, CCB2, CCB3 and CCB4; (b) specimens $\mathrm{CCBI}, \mathrm{CCBI}$ and $\mathrm{CCBI} 2$

ductility results (the displacement ductility factors) are not in line with the deformability results (the drift ratios). For instance, although the specimen CCB3 has the smallest displacements at peak load and at ultimate state (and hence the smallest drift ratios), its displacement ductility factor is not the lowest because its displacement at yield is relatively low.

Comparing the beam specimens CCB1, CCB11 and CCB12, which have the same span/depth ratio but different reinforcement layouts, it is seen that they have displacement ductility factors of $4 \cdot 0,4 \cdot 0$ and $4 \cdot 3$, respectively, and ultimate drift ratios of 5.7, $5 \cdot 4$ and $4 \cdot 3 \%$, respectively. Hence, roughly speaking, they have similar ductility and similar deformability. More importantly, the provision of diagonal reinforcement in the beam specimen CCB11 had not increased the deformability of the coupling beam. Nevertheless, it should be emphasised that a deformability of around 5\% drift is not really small. Subject to confirmation by pushover analysis or non-linear dynamic analysis, it is the authors' belief that a drift ratio of 5\% for the coupling beams should be enough to provide the demanded storey drift for earthquake resistance. If the authors' belief is right, then both conventionally reinforced and diagonally reinforced coupling beams may be designed to have sufficient deformability to withstand earthquake loads.

\subsection{Energy dissipation capacity}

Energy dissipation capacity is another important factor in the evaluation of seismic performance. Here, two measures of energy dissipation capacity are adopted: $(a)$ the amount of energy dissipated in each half load cycle, and $(b)$ the ratio of the amount of energy dissipated to the amount of energy stored in each half load cycle. The amount of the energy dissipated in each half load cycle, $W_{d}$, is defined as the area enclosed by the load-displacement curve and the horizontal axis in one loading direction during the load cycle. The amount of energy stored, $W_{s}$, is defined as the area between the branch of the load-displacement curve starting from zero load to the point of maximum displacement and the horizontal axis in one loading direction during the load cycle. An illustration of these definitions is presented in Fig. 9. $W_{d}$ is the actual amount of energy dissipated, but since a stronger member tends to have a higher value of $W_{d}$, it is dependent on member size and is not really a good measure of energy dissipation efficiency. On the other hand, the ratio $W_{d} / W_{s}$, which is dimensionless and independent of member size, is a much better measure of energy dissipation efficiency.

Figure 9 plots the $W_{d}$ and $W_{d} / W_{s}$ values against the number of load cycles for the six beam specimens tested in the positive loading direction. (The corresponding results for the specimens in the negative loading direction are similar.) Comparing the $W_{d}$ values of CCB1, CCB2, СCB3 and CCB4, it is seen that among the conventionally reinforced coupling beams, the deeper coupling beams generally dissipated more energy. Comparing the $W_{d}$ values of CCB1, CCB11 and CCB12, it is seen that the diagonally reinforced coupling beam dissipated far more energy than the conventionally reinforced coupling beams with the same physical size and span/depth ratio. From the $W_{d} / W_{s}$ results of the six beam specimens, it is evident that even taking the difference in strength into account, the diagonally reinforced coupling beam was still the best in energy dissipation. Nevertheless, the $W_{d} / W_{s}$ values of all the coupling beams tested gradually increased with the number of load cycles, indicating that all the coupling beams were able to maintain their energy dissipation efficiency until very large displacement.

In the conventionally reinforced coupling beams, the amounts of energy dissipated were not the same in the three load cycles at the same displacement amplitude. During the three load cycles, 

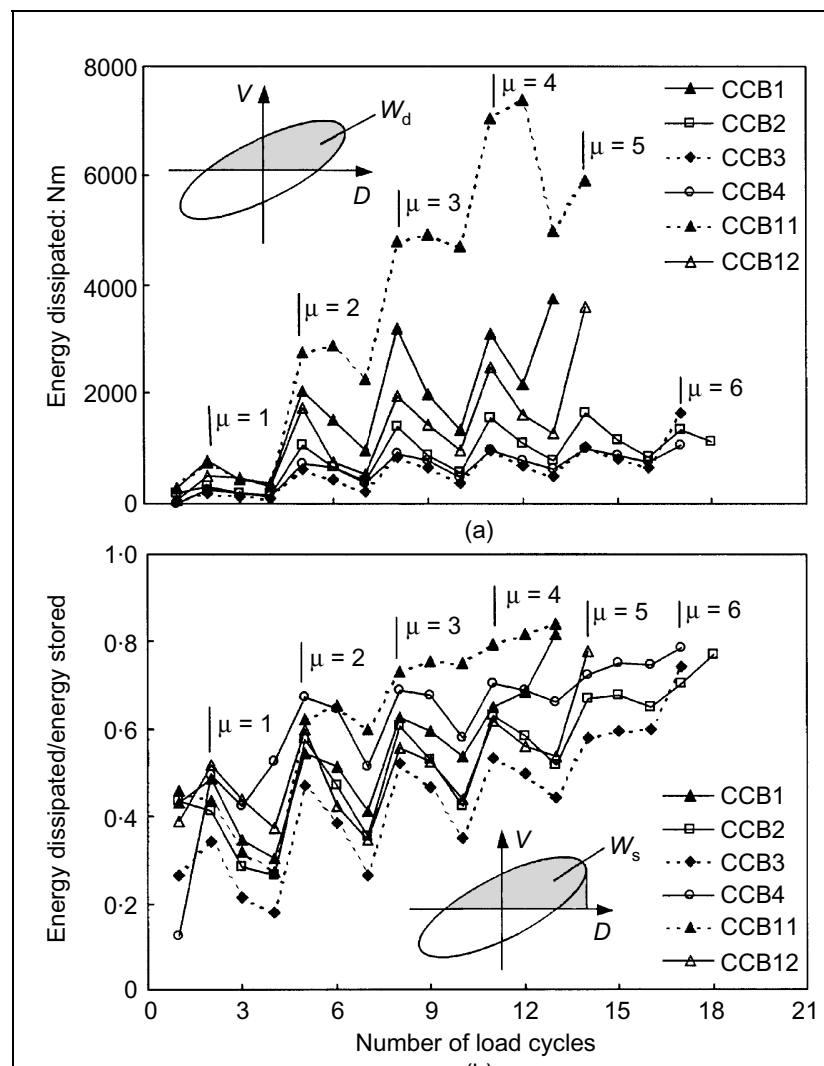

(b)

Fig. 9. Variations of $W_{d}$ and $W_{d} / W_{s}$ with the number of load cycles: (a) energy dissipated; (b) energy dissipation efficiency

the amount of energy dissipated decreased with the number of cycles to such an extent that the amount of energy dissipated in the third cycle was only about $1 / 2$ to $1 / 3$ of that in the first cycle. Since the displacement amplitudes of the three load cycles were the same and the peak loads during the three load cycles had only changed slightly, the difference in energy dissipation was due mainly to the change in the shape of the load-displacement curves. In the diagonally reinforced coupling beam, however, the amount of energy dissipated in each cycle remained fairly constant during the three load cycles at the same displacement amplitude. Hence, the energy dissipation capacity of the diagonally reinforced coupling beam was relatively stable until it failed suddenly by diagonal bar buckling.

\section{CONCLUSIONS}

The test results of the six reinforced concrete coupling beams with span/depth ratios $\leqslant 2 \cdot 0$ revealed that they behaved quite differently from ordinary frame beams. After the appearance of inclined shear cracks, the load resisting mechanism of the conventionally reinforced coupling beams gradually changed with all the longitudinal reinforcement bars becoming in tension and the beams starting to elongate. No zero stress zones existed in the longitudinal reinforcement bars anywhere inside the beams. The elongation strains of the beams were of the order of $1 \cdot 5-2 \cdot 5 \%$.

The measured maximum nominal shear stresses of the conventionally reinforced coupling beams ranged from $3 \cdot 15$ to
4.74 MPa, while that of the diagonally reinforced coupling beam was equal to $5.01 \mathrm{MPa}$. Such high nominal shear stresses led to the tendency of the deep coupling beams to fail in shear. Careful detailing to avoid shear failure is thus of utmost importance in the design of deep coupling beams. Moreover, since the additional longitudinal reinforcement bars can contribute significantly to the load carrying capacity of a coupling beam, their presence should be considered in the evaluation of the shear demand during the beam design.

The displacement ductility factors of the six coupling beams tested varied from $4 \cdot 0$ to $6 \cdot 0$, being generally higher at a larger span/depth ratio. On the other hand, the ultimate drift ratios ranged from 3.6 to $5 \cdot 7 \%$. Additional displacement due to the local rotations at the beam-wall joints had contributed about half to the total lateral displacement and resulted in the above relatively high drift ratios. It is the authors' belief that in the design of earthquake resistant structures, deformability is more important than ductility. Although the ductility factors achieved by the deep coupling beams are relatively low, the above drift ratios should be good enough to provide a reasonable deformability during earthquakes.

Among the coupling beams tested, the diagonally reinforced coupling beam had a more stable hysteretic load-displacement curve and a much better energy dissipation capacity. However, its drift ratios were only about the same as those of the conventionally reinforced coupling beams with the same span/ depth ratio. Hence, the provision of diagonal reinforcement had not improved the deformability of the coupling beam. There was also the problem that the diagonally reinforced coupling beam finally failed due to buckling of the diagonal reinforcement bars. Therefore, sufficient lateral hoops should be provided along the diagonal reinforcement bars to keep the surrounding concrete in place and prevent, or at least delay, buckling failure.

\section{ACKNOWLEDGEMENT}

The financial support from the Research Grants Council of Hong Kong (Project Ref. HKU 7005/00E) for the research reported herein is gratefully acknowledged.

\section{REFERENCES}

1. PaUlay, T. Coupling beams of reinforced concrete shear walls. Journal of Structural Division, ASCE, 1971, 97(ST3), 843-862.

2. PAUlay, T. Simulated seismic loading of spandrel beams. Journal of Structural Division, ASCE, 1971, 97(ST9), 2407-2419.

3. PAUlay, T. and BinneY, J. R. Diagonally reinforced coupling beams of shear walls. ACI Special Publication SP-42: Shear in Reinforced Concrete. American Concrete Institute, 1974, Vol. 2, Detroit, USA, pp. 579-598.

4. BARney, G. B., Shiu, K. N., RabBat, B. G., Fiorato, A. E., Russel, H. G. and CORLEY, W. G. Behavior of coupling beams under load reversals. Research and Development Bulletin RD068.01B, Portland Cement Association, USA, 1980.

5. TAssios, T. P., MoRetTI, M. and BezAs, A. On the behavior and ductility of reinforced concrete coupling beams of shear walls. ACI Structural Journal, 1996, 93(6), 711-720.

6. Galano, L. and Vignoli, A. Seismic behavior of short 
coupling beams with different reinforcement layout. ACI Structural Journal, 2000, 97(6), 876-885.

7. KWAN, A. K. H. and ZHAO, Z. Z. Reinforced concrete coupling beams: their differences from ordinary beams. Proceedings of the 7th International Conference on Enhancement and Promotion of Computational Methods in Engineering and Science, Macao, China, 1999, Vol.1, pp. 581-588.

8. KWAN, A. K. H. Local deformations and rotational degrees of freedom at beam-wall joints. Computers \& Structures, 1993, 48(1), 615-625.

9. AKtan, A. E. and Bertero, V. V. Seismic response of r/c frame-wall structures. Journal of Structural Engineering, ASCE, 1984, 110(8), 1803-1821.

10. Paulay, T. and SANThaKumar, A. R. Ductile behavior of coupled shear walls. Journal of Structural Division, ASCE, 1976, 102(ST1), 93-108.

11. SöZEN, M. A. Review of earthquake response of R.C. buildings with a view to drift control. State of the art in
Earthquake Engineering 1981: Panel Reports for 7th World Conference on Earthquake Engineering (ERGNAY, 0. and ERDIK, M. (eds)). Istanbul, 1980, Ankara, 1981, 383-418.

12. MunshI, J. A. and GHosh, S. K. Displacement-based seismic design of coupled shear wall systems. Earthquake Spectra, 2000, 16(3), 621-642.

13. BоOTH, E. D., KAPPOS, A. J. and PARK, R. A critical review of international practice on seismic design of reinforced concrete buildings. The Structural Engineer, 1998, 76, No. 11, 213-220.

14. KWAN, A. K. H. and ZHAO, Z. Z. Testing of coupling beams with equal end rotations maintained and local joint deformation allowed. Structures and Buildings, Thomas Telford, London, 2001, 152, No. 1, 67-78.

15. American Concrete Institute Committee 318. Building Code Requirements for Structural Concrete (ACI 318-95) and Commentary (ACI 318R-95). ACI, Farmington Hills, Michigan, USA, 1995.

Please email, fax or post your discussion contributions to the secretary by 2 January 2003: email: lyn.richards@ice.org.uk; fax: +44 (0)20 7799 1325; or post to Lyn Richards, Journals Department, Institution of Civil Engineers, I-7 Great George Street, London SWIP 3AA. 